\title{
Chapter X. Understanding the governance structures that underpin responsible investment decision-making
}

Heather Hachigian, Carleton Centre for Community Innovation |E: hhachigian@gmail.com

Keywords: Governance; responsible investment; decision-making; investment beliefs; reflexivity

\section{Introduction}

The aim of this essay is to consider the extent to which best practice governance can be adapted to support effective responsible investment (RI) decision-making. Governance refers to the mechanisms and processes by which decision-making is managed. Best practice governance emphasizes institutional coherence, expertise and effective processes of deliberation (Clark and Urwin 2008). The essay focuses on institutional investors with long-term investments horizons, such as pension funds, endowments and sovereign wealth funds. As universal owners, it is widely held that these investors must incorporate relevant environmental and social issues into their investment decision-making to achieve their investment objectives. ${ }^{1}$

This essay argues that adding environmental and social dimensions to the already complex process of investment decision-making requires increasing and on-going investment in an investor's own governance. The form of governance required depends on the perspective motivating an investor's RI strategy. The literature can be divided broadly into two perspectives. The first perspective suggests that investors should limit their consideration to environmental, social and governance (ESG) issues that are underpinned by a sound business case in the form of a financial risk or opportunity. A second perspective suggests that financial risks and opportunities at the portfolio level

\footnotetext{
${ }^{1}$ Universal owners hold diversified and long-term portfolios that are representative of global capital markets. Therefore, universal owners cannot ignore the externalities associated with individual investments.
} 
cannot always meaningfully be separated from broader political, ethical and sustainability issues. This second perspective requires that investors adopt a more reflexive form of governance to understand how their own decision-making frameworks interact with and contribute to shaping risks and opportunities at the systems level.

\section{Business case perspective of investment decision-making}

The business case perspective, which historically has dominated the RI literature, suggests that trustees have a fiduciary obligation to take into account material ESG information in their investment decisions. Materiality refers to a substantial likelihood that disclosure would impact an investor's decision. The concept relies on traditional corporate valuation parameters for determining financial impact. ${ }^{2}$ There is an emerging consensus among academics that, at least over the long-term, companies with strong material ESG performance demonstrate enhanced operational performance and are considered to be less risky. The business case has been widely influential in institutional investors' adoption of RI policies.

\section{Governance challenge for the business case}

The governance challenge facing institutional investors seeking to implement an RI strategy, like the challenge facing any investor, is making decisions and managing risk in the context of complex and rapidly changing global financial markets. Asset owners often delegate significant responsibilities for investment decisions to the asset management industry, which in turn, delegates responsibility for selecting and implementing productive projects to corporate managers. The governance challenge is often framed in principal-agent terms, where ESG information asymmetries inhibit market efficiency.

\footnotetext{
2 As a legal concept, the US supreme court defines information as material if there is a "substantial likelihood that the disclosure of the omitted fact would have been viewed by the reasonable investor as having significantly altered the 'total mix' of information made available". This definition informs the Sustainable Accounting Standards Board (SASB) reporting framework.
} 


\section{Best practice governance for the business case}

From the business case perspective, it is assumed that implementing an RI strategy requires only limited change to an asset owner's existing governance processes. For example, Woods and Urwin (2010) adapt Clark and Urwin's (2008) best practice governance to inform a practical framework for pension funds seeking to implement a RI strategy. Their framework allows investors to integrate material ESG issues, while noting that non-financial (e.g., ethical) concerns should only be addressed by investors that are not bound by fiduciary duty. Moreover, it is widely held that trustees should delegate authority for investment decision-making to independent experts to ensure depoliticized decision-making.

Among the changes to governance that are required for a RI strategy, Woods and Urwin recommend that trustees identify the resources necessary for the investment strategy, promote strong leadership to manage conflicting views, implement a risk budget framework to capture quantifiable ESG risks and ensure asset mangers have appropriate skills to integrate ESG issues. Their framework pays close attention to two dimensions of governance: clarity of mandate and investment beliefs.

Clarity of mandate: When implementing a RI strategy, investors should adopt a RI mission statement that aligns with their other mission statements. Moreover, the commitment of all agents in the asset management chain to the RI mandate is considered essential. Securing this commitment requires asset owners to assess the ESG skills of managers, integrate ESG reporting expectations into mandates and ensure that the management and selection of ESG issues are integrated into performance reviews.

Investment beliefs: Securing this commitment also requires asset owners to ensure that investment mandates align their managers' investment approach with their own investment beliefs. Explicitly stated investment beliefs that are evaluated against future scenarios are essential to an effective RI strategy. While Woods and Urwin note that uncertainty and ambiguity are problematic for forming investment beliefs related to some ESG issues, they distinguish between the subjective investment beliefs of naïve investors 
and the investment beliefs of experts. Implicit in this argument is that experts can reduce uncertainty and ambiguity to risk by using the machinery of probability. The authors predict that at some point the goals of RI will become internalized into institutional investors' belief systems as fiduciary duty standards evolve to reflect new norms underpinning investment.

\section{Integrated perspective of investment decision-making}

There are, however, reasons why fiduciary duty may not evolve in the way suggested above. As a standard for investment behavior, scholars often point out that fiduciary duty looks to convention rather than innovation. This does not mean that the legal concept is itself static. Interpretations of fiduciary duty evolve to reflect interests of those with power to shape its interpretation. As such, Clark et al. (2015) suggest that government has a role to play in clarifying fiduciary duty in ways that protect the interests of vulnerable groups, such as future generations. Some scholars go so far as to argue that the business case has reached its limits, citing examples of where the business case fails to provide for meaningful action on ESG issues that manifest at the systems level and that interact with and shape portfolio level risks. ${ }^{3}$

This second, integrated, perspective implies that investment strategies that focus solely on portfolio-level risks and opportunities are insufficient to achieve long-term financial return objectives. Some scholars have placed emphasis on the ethical dimensions for ESG investing, noting that ethical motivations can encourage investor action when the business case fails. Other scholars emphasize the long-term and draw attention to the importance of considering broader sustainability issues for which materiality is indeterminate or ambiguous at the portfolio level. For example, a long-term perspective requires pension funds to pay attention to consequences of issues like climate change

\footnotetext{
3 The Investment Integration Project encourages investors to consider how systemic-level issues interact with and shape risks and opportunities at the portfolio-level. For an overview of the framework, see Lydenberg, S. (2015). Portfolios and Systemic Framework Integration: Towards a Theory and Practice. Exposure Draft, November 2015.
} 
over several decades to fulfill their responsibility to balance the interests of current generations with future generations.

\section{Governance challenge for the integrated investment perspective}

While different philosophical approaches underpin this second perspective, these approaches share an appreciation for the ambiguity inherent in modern investment decision-making. Ambiguity is a problem of interpretation, rather than a problem of information. Problems of interpretation arise because complexity and interdependence obscures efforts to measure risks using conventional finance tools that rely on probabilistic reasoning. In other words, decision-makers do not have sufficient information about the structure of the problem they are trying to solve. ${ }^{4}$ Therefore, the Bayesian decision-making model that explains how decision-makers transform uncertainty and ambiguity into risk by learning and updating their beliefs overestimates what agents can learn under changing and complex environments. ${ }^{5}$

To make this discussion more concrete, consider the example of climate change. Adopting a business case perspective allows investors to focus on specific aspects of climate change risk at the individual company and the portfolio level. Investors can make decisions based on their beliefs about the probability of climate change policies eliminating oil and coal reserves from corporate balance sheets or increasing the risk associated with the portfolio's carbon intensity. Moreover, investors can find solace in the certainty of their decisions and can justify their decisions to others. But in doing so, decision-makers necessarily ignore complex interactions that cannot be quantified and understood in probabilistic terms.

\footnotetext{
4 For example, "Calibrating the geographical impact of climate change thereby discriminating between regions of the earth on the basis of likely environmental conditions over the next 20,50 to100 years remains a significant challenge (Clark et al. 2015b, 604)."

${ }^{5}$ For an example of decision-making under changing and complex environments, see Epstein, L G and Schneider, M (2007) Learning under ambiguity. The Review of Economic Studies, 74(4): 1275-1303
} 
For example, carbon footprinting is intended to help investors to shift their portfolios into investments with lower carbon intensities and to reduce climate change risks to their portfolio. While these metrics can provide investors with information to determine which investments to shift away from, critics note that the analysis often omits consideration for a company's future strategies. A company that is a heavy user of fossil fuel but that intends to launch a new energy project or technology that could have system-wide impacts on the reduction of carbon emissions may not have access to capital to implement the project.

To address these limitations, investors and their agents must be allowed to use their discretion. For example, the Montreal Carbon Pledge includes consideration for a corporation's future climate change strategy alongside its emissions, and a recommendation that investors or their agents undertake further qualitative analysis. ${ }^{6}$ This discretion allows room for evaluating investments at both the portfolio and the systems level. But discretion also introduces new governance challenges. Subjective evaluations that rely on human judgments and interpretations can introduce behavioural biases, strategic interpretation and political interests into investment decision-making; those pathologies that the financial industry has sought to eradicate.

An example of how these pathologies can manifest is the strategic interpretation of corporate sustainability ratings. The Centre for Political Accountability (CPA) rankings of political spending disclosure practices of S\&P 500 companies are intended to provide investors with information to make better decisions and to ensure that political spending benefits the company rather than the personal interests of corporate managers. In a brief advising corporate managers on how to respond to shareholder proposals on political spending, a law firm promotes its services to "help companies be perceived by these group as good corporate citizens... without altering current practices." ${ }^{7}$

\footnotetext{
6 http://montrealpledge.org/

${ }^{7}$ Covington \& Burling LLP claims that it can "provide clients with the lest invasive and least intrusive disclosures they can make and still receive full credit. This lowest denominator approach can help companies increase their scores without adding unnecessarily burdensome compliance and information gathering systems." See page 16, Corporate Governance Advisor, Volume 32, Number 2. March/April 2015.
} 
It is often assumed that opportunities to exploit such market inefficiencies will be resolved over time, as institutions and organizational forms evolve to correct for transaction frictions and behavioural distortions. For example, the Sustainability Accounting Standards Board aims to eliminate ambiguity in corporate sustainability reporting by supplying the market with a comprehensive set of standards. But who holds the standard setters accountable ${ }^{8}$ Moreover, it is possible that market institutions can remain 'locked in the past', as standards of performance used to evaluate asset managers and consultants tend to discount innovation in favour of arrangements that are considered legitimate (Clark and Monk 2015).

Another way that investors can reduce market inefficiencies is by using relational contracts to promote mutually beneficial behavior by invoking a long-term relationship. Given the risk and uncertainty that characterizes financial markets, relational contracts are common in the investment management industry. There is an implicit assumption in the relational contracting literature that the parties share an understanding of the promise underlying the relational contract. But what if they do not share the same understanding? An ambiguous understanding of the promise underlying the relational contract provides room for interpretation of contracts in ways that can be more beneficial to one party than to the other. This clarity problem draws attention to the possibility that reasonable people can hold different understandings of a relational contact, even over the long-term (Gibbons and Henderson 2013).

Consider the potential for different understandings between asset managers and asset owners. Asset managers and consultants are often in a privileged position relative to their clients due to network effects and informational advantages. That is, by virtue of repeated transactions and interactions, intermediaries often have access to better information and better relationships than their clients. This positioning allows intermediaries to interpret

\footnotetext{
8 As noted in a letter to SASB dated July, 2016 authored by the Investor Environmental Health Network, "the practical reality is that as a market leader, SASB and its standards do not only provide information that investors seek - it effectively plays the role of advising investors as to the type of information that they should seek".
} 
institutional arrangements (e.g., contracts) in ways that align with their own interests, often at the expense of their clients' long-term interests. Contrary to best practice governance, clarity of an RI mandate across the asset management chain is not always possible.

As these examples demonstrate, the ability to see and to act in shades of grey is increasingly important in complex and interdependent financial markets. But so is the ability to justify decisions in black and white. The tension between these two imperatives lies at the heart of the governance challenge for the integrated investment perspective.

\section{Best practice governance for the integrated investment perspective}

The integrated investment perspective requires a deeper commitment to the governance of decision-making than the business case perspective. In particular, the integrated investment perspective requires adapting decision-making frameworks to contexts where uncertainty and ambiguity cannot be reduced to risk by using subjective probabilities, or eliminated with standards and relational contracts.

One response to the governance challenges facing asset owners in complex environments has been to bring investment management in-house to ensure closer control over decisions. A key dimension of success with this strategy is the ability to offer competitive pay in order to attract talent. For many smaller funds that lack resources and capabilities, bringing investment management in-house is not a viable option. Moreover, despite their challenges, intermediaries also provide significant benefits. For example, Clark and Monk (2015) find that investment consultants complement investors' resources and capabilities and are essential to innovation and success in complex decision-making environments.

Recognizing the value of intermediation in complex investment environments, governance of RI decision-making from the integrated perspective requires asset owners to manage and to negotiate competing interpretations of complex and evolving sets of 
information with the asset management industry. Key to success is reflexivity. As a governing principle, reflexivity requires institutional investors to understand how their own decision-making frameworks interact with and contribute to shaping systemic-level risks and opportunities and to learn from their mistakes (Clark et al. 2015).

In practical terms, investors can exercise reflexivity in reviewing investment beliefs and strategies of their managers and assessing ESG skills and performance of their managers. For example, reflexivity allows asset owners to see the inherent contradiction between short-term performance metrics often used to evaluate their managers and the long-term ESG investment mandates that are awarded to these same managers. Similarly, reflexivity allows asset owners to recognize that it is insufficient to award an ESG mandate to managers without also dedicating resources to on-going monitoring and dialogue with managers to ensure a shared understanding of the mandate against evolving and complex investment contexts.

\section{Conclusion}

This essay has argued that the form of governance required for effective decision-making depends on the perspective that is motivating the investor's RI mandate. Investment decision-making that is motivated by the business case can be managed by adapting traditional governance frameworks that emphasize de-politicized decision-making and clarity of mandate. But those investors that view their investment decisions as interdependent with broader financial, environmental and societal systems will need to make greater investments in their governance to manage investment decision-making in a complex environment. This is because market efficiency is inhibited, not only by problems of information but also, by problems of interpretation. This essay has focused on the potential lack of clarity of the RI mandate across the asset management chain and the importance of reflexivity in governance. More research is needed to understand how other aspects of governance, such as leadership, incentive design and systems of deliberation can cope with the ambiguity inherent in complex decision environments. 


\section{References}

Clark G L, Hachigian H, McGill S, Molinari C and Wojcik D (2015) Addressing the challenges of transformation. In: Hebb, T et al. (eds.) The handbook of responsible investment. Routledge, $p$ 593-609

Clark G. L. and Monk A. H (2015) Investment advisers and consultants: Ambiguity, contract, and innovation in response to changing circumstances. Available at SSRN: http://ssrn.com/abstract=2588424. Accessed 15 Aug 2016

Clark G L and Urwin R (2008) Best-practice pension fund governance. Journal of Asset Management, 9(1):2-21

Gibbons, R. and Henderson, R. (2013). What do managers do? Exploring persistent performance differences amongst seemingly similar enterprises. In Gibbons R and Roberts J (eds) The handbook of organizational economics. Princeton University Press, Princeton, p 680-731

Woods C and Urwin R (2012) Putting sustainable investing into practice: A governance framework for pension funds. In Hebb, T (ed) The next generation of responsible investing. Springer, Netherlands, p 27-48 